\title{
Web-based Online Sales
}

\author{
M Zaka ${ }^{1}$, R Yunanto ${ }^{*}$ \\ ${ }^{1}$ Departemen Sistem Informasi, Universitas Komputer Indonesia, Indonesia \\ 2Departemen Komputerisasi Akuntansi, Universitas Komputer Indonesia, Indonesia \\ Email: *rio.yunanto@email.unikom.ac.id
}

\begin{abstract}
The purpose of this research is to design an online sales website in the fashion field to increase sales at the Fashionku store. The research method used a waterfall method by observing and designing a web-based system, which uses the help of XAMPP software as well as analytical tools using PHP, HTML, and CSS. The research results show that website design for Fashionku online sales. The existence of online websites for Fashionku stores is expected to increase sales. Product innovation, distribution of advertisements, and website appearance with complete features are things that will attract the attention of customers to buy products.
\end{abstract}

\section{Introduction}

The development of information technology in terms of buying and selling goods online in Indonesia has been growing rapidly. E-commerce is inseparable from the development of business and the economy in Indonesia at this time. E-commerce, which is electronic commerce is the process of marketing, selling, promoting, exchanging goods, buying, and selling goods or services through the internet network. E-Commerce can be defined as an arena for transactions or exchanges of information between sellers and buyers in cyberspace. Ecommerce allows a company to reach all over the world to market its products or services without having to be limited by geographical boundaries [1]. E-commerce is about how someone builds a business on the internet, which is followed by entrants who access the website created and go to the catalog of products or services offered [2]. An individual or company that wants to develop its business, needs to participate in e-commerce, which is offering and selling its services online. Therefore, opportunities are created for various aspects that offer new efficiencies in terms of product marketing, sales, customer service, shipping tracking, stock monitoring, and so on [3]. The website is a platform for offering and selling service goods online. The website can be defined as a medium for delivering information on the internet as a provider of commercial information or online stores, services, and delivering news [4]. The website created and formed from a series of specific codes or scripts from certain programming languages [4]. The programming language that usually used is PHP, HTML, CSS, ASP.Net, Java, static files, ClodFusion, Ruby, JavaScript, Perl, Python, and Erlang. To facilitate website design, PHP is usually used as a programming language for websites. 
E-commerce can simplify the transaction process in purchasing products and customers can see directly new products in E-Commerce so that the purchasing process can be done quickly [5]. The website development makes it easy for customers to get information about products sold. Customers can also easily access the forum for offering and selling the latest products, anywhere and anytime they want to buy goods [6]. Online website design can provide services as a marketing tool that can help business owners in expanding their internet-based business and make the product warehouse section more integrated when there is online stock on the website [7]. In designing online websites to sell goods, it needs to be taken into account regarding customer tastes, the need for new products, and the design of features that are easily accessible [8]. With web-based sales, all information about store products can be accessed quickly without having to come to the store location as well as a broad reach that can reach all over the world, can reduce costs incurred regarding product advertising and marketing, making it easy for business owners to interact directly with customers, and easy in processing data items and making sales reports [9]. The quality of the web designed is determined by habits, trust and perceived usefulness [10]. E-commerce in retail companies is currently pursuing more profit from the internet on the grounds of reducing costs in operations and the existence of customer reactions to virtual offerings, the need for quality improvement, and renewal of the web [11]. There are supporting factors in building websites that attract the interest of customers namely in terms of appearance, understanding, accessibility, availability, credibility, and communication [12]. The existence of e-commerce provides flexibility for anyone who wants to run their business wherever they are and at a small cost that revealed the opportunities in e-commerce. It allows for enormous operational efficiency, informationbased products, and services as a marketing complement for companies [13,14]. E-commerce makes customers easier to increase choices and the features of the problem solver they are facing online [15].

The purpose of this paper is to design an online sales website in the fashion field to increase sales at the Fashionku store. This research used a waterfall method by observing and designing a web-based system, which uses the help of XAMPP software.

\section{Method}

This research used a waterfall method by observing and designing a web-based system, which uses the help of XAMPP software as well as analytical tools using PHP, HTML, and CSS. The waterfall method, also known as the classic life cycle, describes a systematic and sequential approach in software development. Starting with preparing the specifications of user needs, then through the stages of planning, modeling, construction, to deployment.

\section{Results and Discussion}

The main page provides features for women's, men's fashion, fashion catalog, search engine, and shopping cart. The main page displays a new arrival, where customers can immediately see the latest output of Fashionku products. At the bottom of the page, there is a feature for my account. Here, buyers can create an account, sign in, track orders, and confirm payment. There are features of customer service. These features are for customers who want to know how to order goods, shipping information, payment information, product return methods, size guides, and other questions to be asked. There is also a link where customers can see the outlet of my fashion store. The main page also has a feature to contact online directly with my fashion shop customer service. Customers can also look around my fashion store's social media (see Figure 1). 


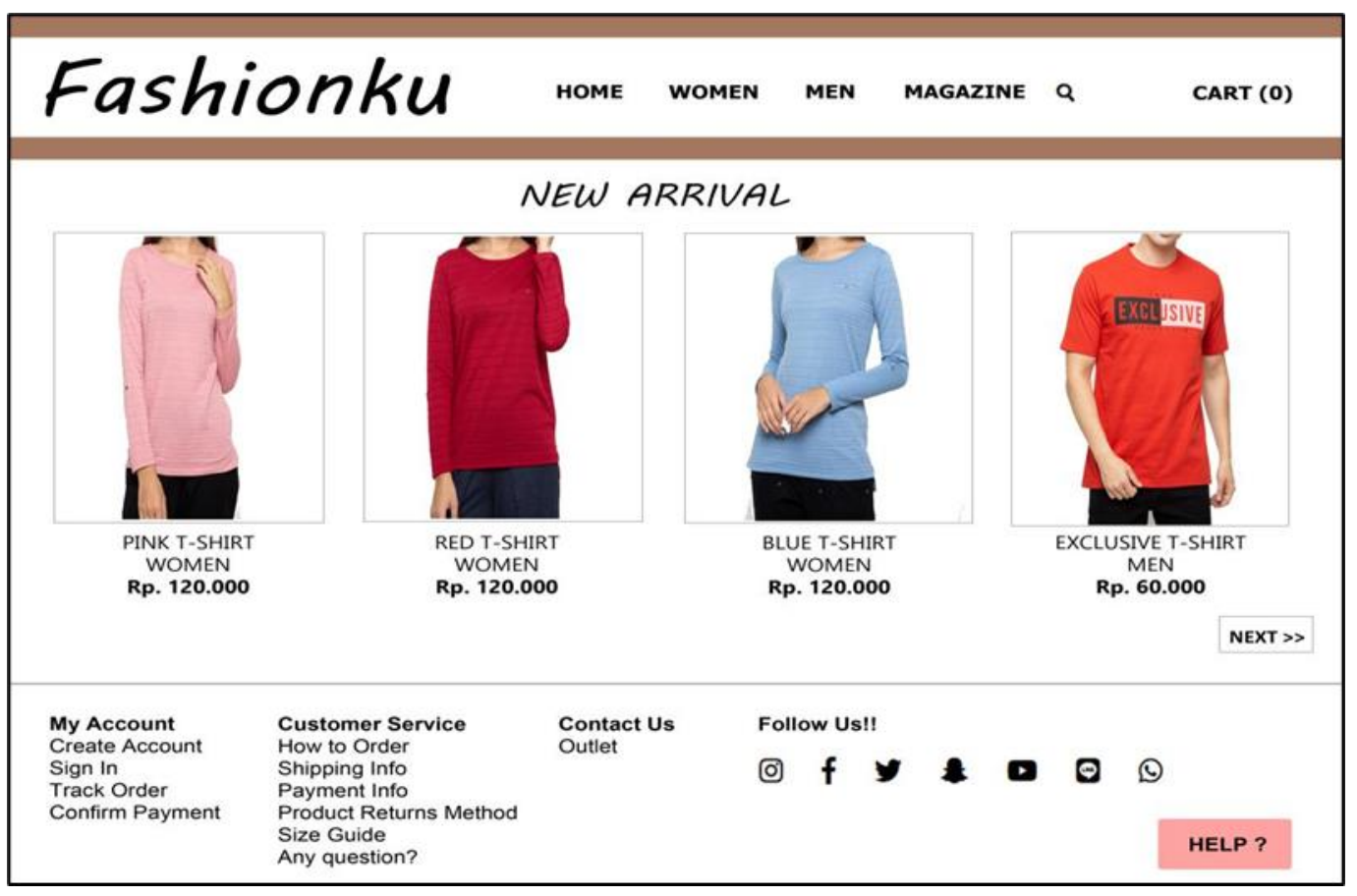

Figure 1. Main page

The goods page shows the items that customers can buy. On this page, customers can choose the size of the desired item, then add it to the shopping cart. It shows that customers must ensure the shape and color of the items to be purchased are as intended. Different item colors are available in the list of available items (see Figure 2).

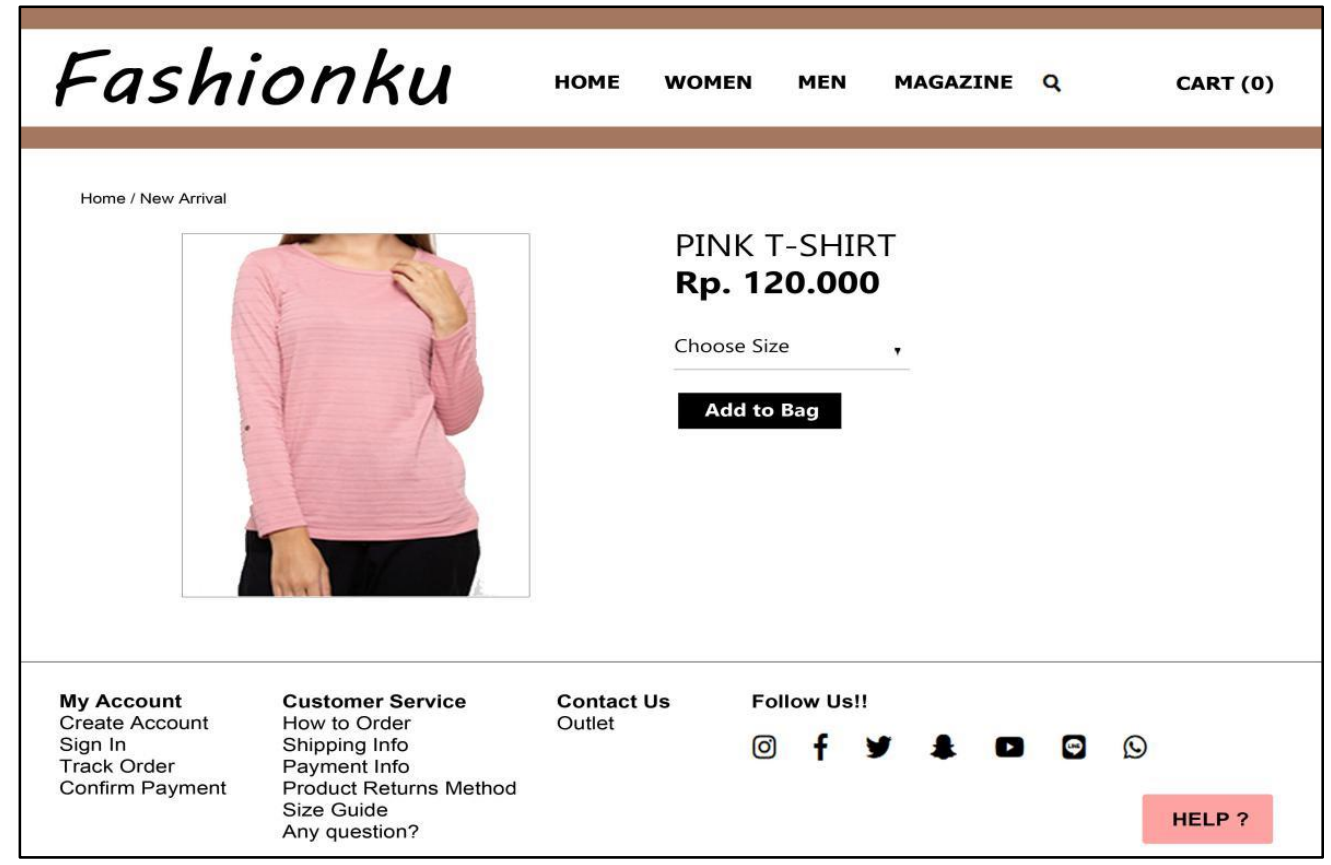

Figure 2. Item Page 
After selecting items placed in the shopping cart, the sign-in page will appear. The sign-in page displays a column for logging into an account, which is equipped with logging in via Facebook and a Google account. It shows that online sales websites have used a single sign-on (SSO) scheme as a method to facilitate customers in managing their online accounts. With the SSO scheme, customers do not need to remember multiple usernames and passwords. They only need to remember one credential to do the authentication process (see Figure 3).

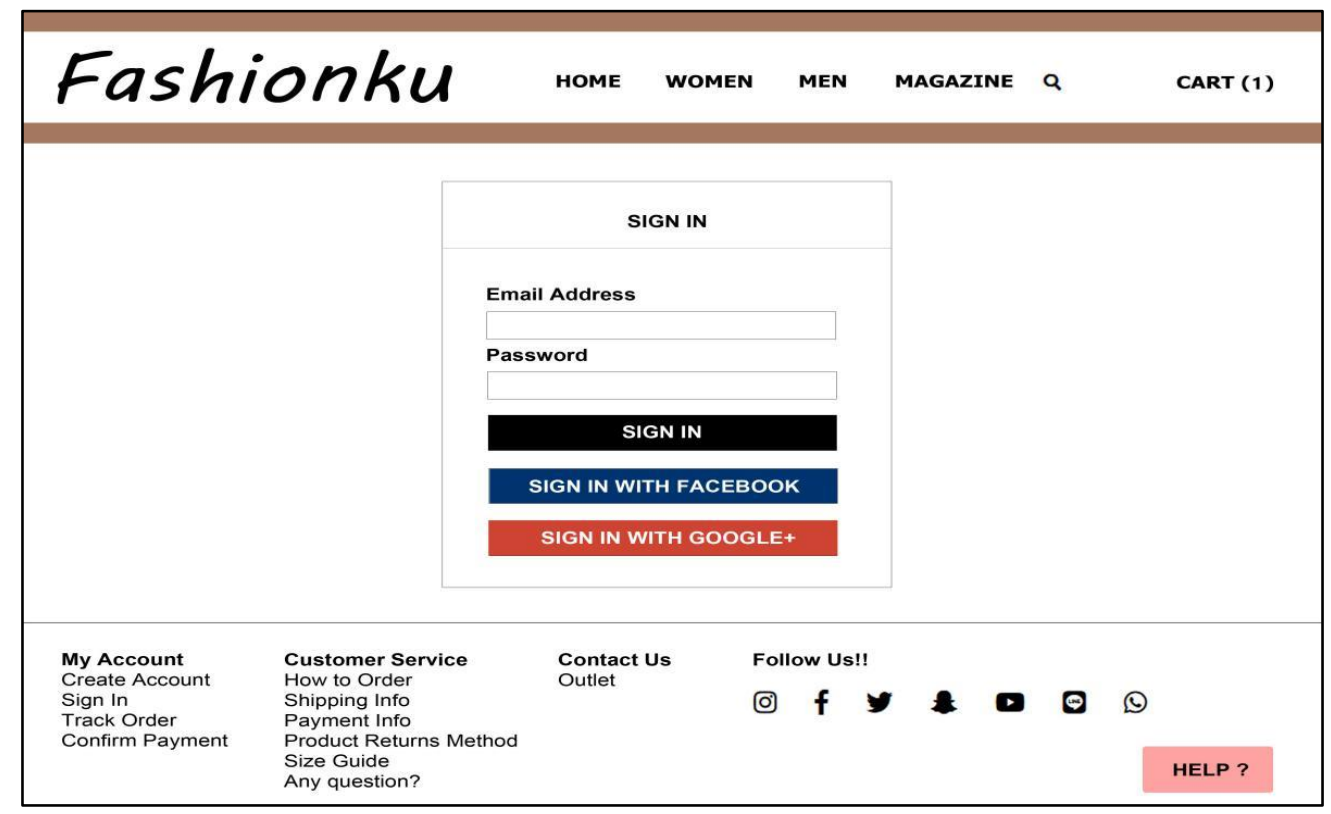

Figure 3. Sign In page

After signing in, a shopping cart page will appear. The shopping cart page displays information about the items that customers want to buy and goes to the payment process. Continue to the payment to display the payment options page that customers want. It shows the total of many items on the shopping cart page will also be calculated automatically, making it easier for customers to make payment transactions (see Figure 4). 


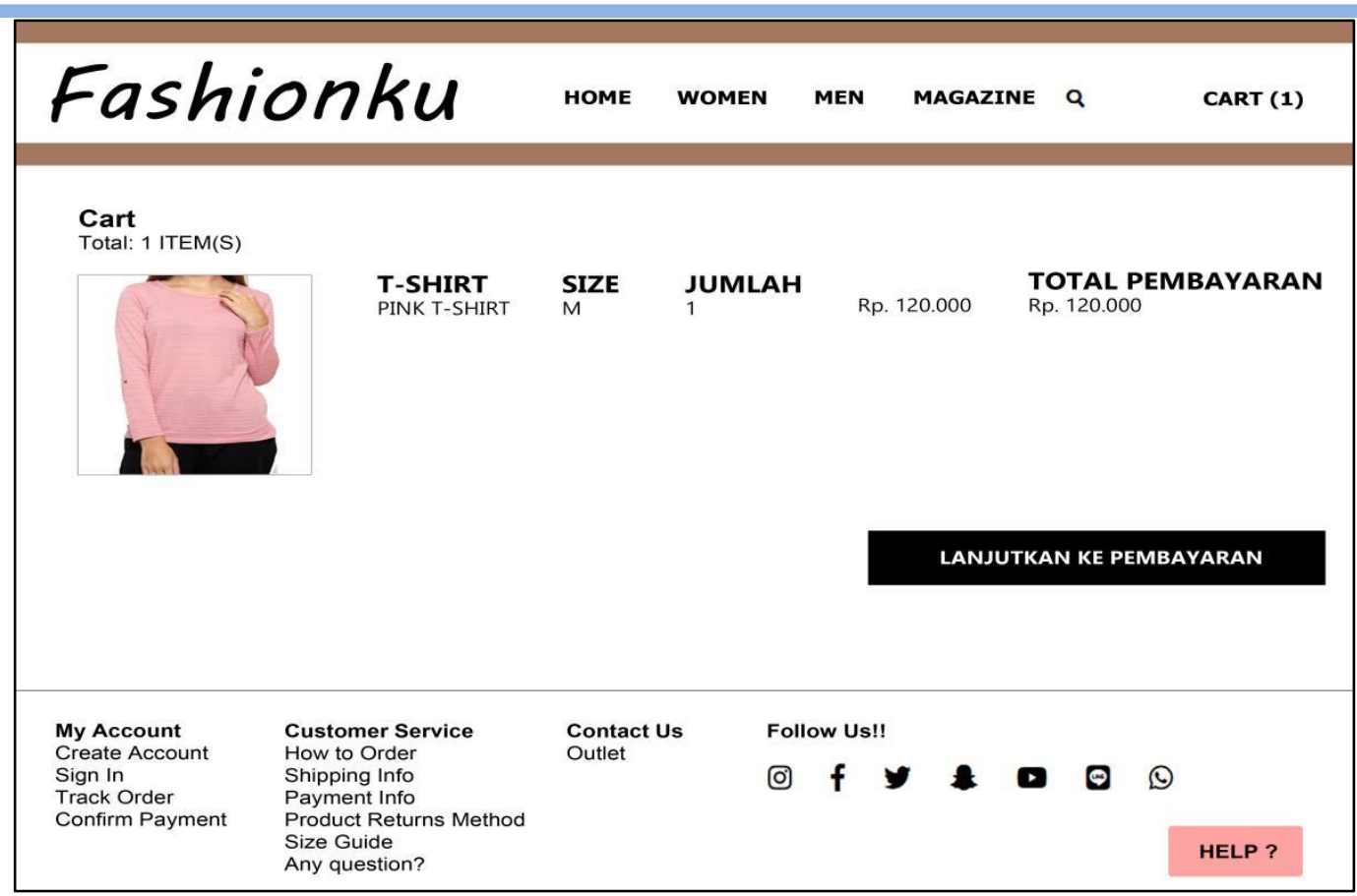

Figure 4. Shopping Cart Page

The payment page displays the total payment for the customer's shopping cart, showing payment options that can be chosen by the customer. It can be seen various choices of banks that can be used by customers according to what they have. Payments using the same bank account will reduce transfer fees between banks (see Figure 5).

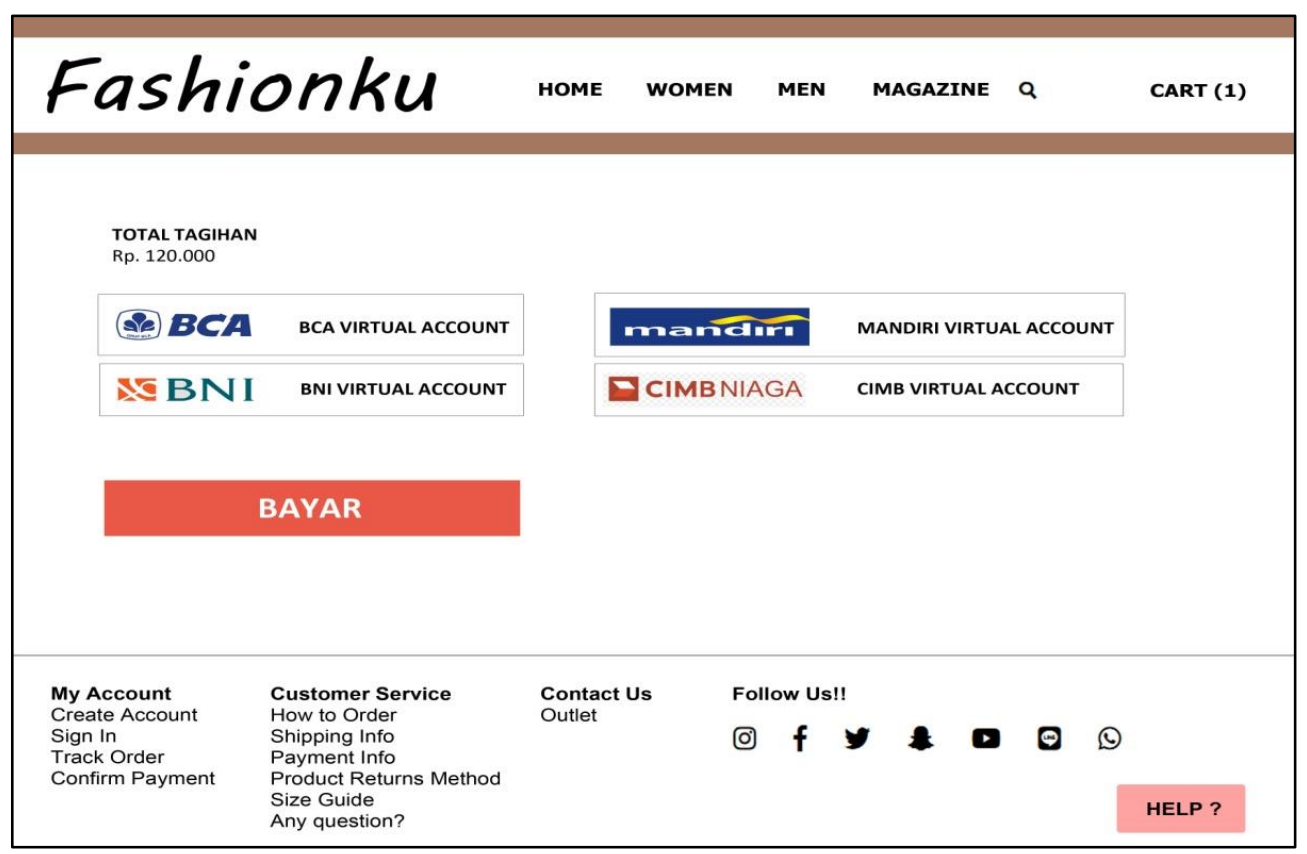

Figure 5. Payment page 


\section{International Journal of Research and Applied Technology}

1(1)(2021) 120-126

Journal homepage: https://ojs.unikom.ac.id/index.php/injuratech

\section{Conclusion}

From the research results obtained, we can conclude that the existence of online websites for Fashionku stores is expected to increase sales. Product innovation, distribution of advertisements, and website appearance with complete features are things that will attract the attention of customers to buy products.

\section{Acknowledgement}

We would like to thank Universitas Komputer Indonesia and those who involved in the process of making this research so that we can complete the research well.

\section{References}

[1] Soegoto, E. S., Christiani, A., \& Oktafiani, D. 2018. Development of E-Commerce Technology in World of Online Business. In IOP Conference Series: Materials Science and Engineering, 407(1), p. 012031.

[2] Soegoto, E. S., \& Eliana, E. 2018. E-Commerce and Business Social Media Today. In IOP Conference Series: Materials Science and Engineering, 407(1), p. 012034.

[3] Soegoto, E. S., \& Puspita, Y. S. 2018. The Security of Transactions on E-Commerce as Media Business. In IOP Conference Series: Materials Science and Engineering 407(1), p. 012180.

[4] Wibawa, J. C., Izza, M., \& Sulaeman, A. 2018. HRIS (Human Resources Information System) Design for Small for Micro, Small and Medium Enterprises. In IOP Conference Series: Materials Science and Engineering, 407(1), p. 012134.

[5] Baghdadi, Y. 2016. A framework for social commerce design. Information Systems, 60, pp. 95-113.

[6] Ahmad, D., Ariessanti, H. D., \& Awaliyah, K. 2017. Implementation of E-Commerce Website to Increase Online Sales of Case Study of Baby Wise BSD Tangerang. Aptisi Transactions on Management, 1(1), pp. 11-16.

[7] Lee, J. H., Lee, J. H., Xiao, J., Desai, M. S., Zhang, X., \& Lee, S. W. 2019. Vertical SelfAssembly of Polarized Phage Nanostructure for Energy Harvesting. Nano letters, 19(4), pp. 2661-2667.

[8] Peterson, J. 2016. The co-design process in mass customization of complete garment knitted fashion products. Journal of Textile Science \& Engineering, 6(4), pp. 1-8.

[9] Soegoto, E. S., Marbun, M. A. S., \& Dicky, F. 2018. Building the Design of E-Commerce. In IOP Conference Series: Materials Science and Engineering, 407(1), p. 012021.

[10] Linzbach, P., Inman, J. J., \& Nikolova, H. 2019. E-Commerce in a physical store: which retailing technologies add real value. NIM Marketing Intelligence Review, 11(1), pp. 42-47.

[11] Satia, F. B., \& Wahab, D. A. 2019. Marketing Services in the Field of Photography and Videography Using Information Technology. In IOP Conference Series: Materials Science and Engineering, 662(3), p. 032062.

[12] Jiang, L., Jun, M., \& Yang, Z. 2016. Customer-perceived value and loyalty: how do key service quality dimensions matter in the context of B2C e-commerce. Service Business, 10(2), pp. 301-317.

[13] Wulandari, T. A., \& Nugraha, Y. I. 2019. The Influence of E-Commerce Information System on Local Product Companies. In IOP Conference Series: Materials Science and Engineering, 662(3), p. 032065. 
International Journal of Research and Applied Technology

1(1)(2021) $120-126$

Journal homepage: https://ojs.unikom.ac.id/index.php/injuratech

[14] Mukharil, A., \& Hanifah, R. N. 2019. Bitcoin influence on E-commerce. In IOP Conference Series: Materials Science and Engineering, 662(3), p. 032037.

[15] Sutisnawati, Y., \& Maulani, W. K. 2019. Big Data Impact in Development E-Commerce. In IOP Conference Series: Materials Science and Engineering (Vol. 662, No. 3, p. 032054). 